\title{
Research on Risk of Online Supply Chain Finance
}

\author{
Daozhi Zhao $^{1}$, Di Wang ${ }^{1}$ and Baosen Wang,** \\ ${ }^{1}$ College of Management and Economics TianJin University, Tianjin China \\ 2School of Economic of Beijing Wuzi University, Beijing China \\ ${ }^{*}$ Corresponding author
}

\begin{abstract}
In recent years, with the deeply combine of "Internet + finance", traditional supply chain finance has also accelerated the pace of online operation, and its risks have gradually been exposed. Therefore, it is necessary to study the risk of the online supply chain finance in order to clarify its characteristics, classification, identification and evaluation and make it better serve the end-customers of the online supply chain finance.
\end{abstract}

Keywords - online supply chain finance; credit risk; operational risk; market risk

\section{INTRODUCTION}

\section{A. The Definition of Online Supply Chain Finance}

Online supply chain finance (OSCF) is an entity based on supply chain finance. It forms a new form of supply chain finance through Internet and informationization, and becomes a complex financial innovation product. The nature of Internet supply chain finance is to regard the core enterprises in the supply chain and their upstream and downstream SMEs as a entity, the industrial chain as the base, focusing on the transaction, the funds allocate as the line, ensuring the risk management, Win-win cooperation as the goal, with the help of internet technology comprehensively develop the financial services throughout the entire financial supply chain[16].

online supply chain finance include the e-commerce transactions, online payment, online financing and logistics management. Financing platform is the core of the online supply chain finance, it can link with e-commerce platform, logistics platform, and payment platform. Linking with e-commerce platform realize the online business and transactions between the enterprises[20]. Linking with logistics management platform achieve the goal of online goods management of enterprise. In addition, linking with payment platform realize the real-time monitoring of bank funds. Therefore, the online supply chain finance has realized the connection between the supply chain enterprises and the financial entities, and the data real-time sharing of enterprises' business activities. As a result, banks can provide supply chain enterprises with great online financial services, and the resources will be optimally allocated[17].

The advantages of online supply chain finance lie in the unification of logistics, business flow, capital flow and information flow, and named "four flows convergence"[24]. Making the core enterprises with upstream and downstream enterprises in the supply chain as an entity, and provide the financial service and financing project, so as to transform the uncontrollable risks of a single enterprise into the risks that can be controlled by the whole supply chain. Moreover, with the real trade background, supply chain finance reduces the demand for commercial banks as a credit intermediary.

\section{B. Sources and Categories of Risk in Online Supply Chain Finance}

The risk comes from the uncertainty, and there are many factors that lead to the uncertainty of supply chain financial ecomode, mainly from the uncertainty of financial eco-environment. External uncertainties in the financial eco-environment include policy uncertainty, economic uncertainty, natural uncertainty and social uncertainty[27]. The uncertainty of the internal environment of the financial environment mainly refers to the immaturity of the Internet technology and the uncertainty of the real data[18].

In addition, the supply chain financial eco-mode has two attributes of industry and finance, so it also has the dual risks from the industrial chain and the financial sector. Due to the large number of participants in the supply chain finance with the long industrial chain, the vertical segmented industrial chains have different attributes and characteristics, the operational procedures are also complicated, and the various factors in the supply chain financial ecology are interdependent and interlocking. Any part of the problem will endanger the normal operation of the entire supply chain[26].

This article roughly divid the online supply chain financial risks into: credit risk, operational risk and market risk.

\section{CREDIT RISK}

\section{A. The Definition of Credit Risk}

Credit risk as the most traditional bank risk is born at the same time with its loan business. Customer loans are the source of the most fundamental credit risk for all banks. Credit risk, also known as the borrower's default risk, mainly refers to the risk that the borrower's debt or bank loans may not be able to repay to the bank and cause some losses due to various reasons. When a default occurs, creditors or banks will certainly bear some financial losses because they have not obtained the expected benefits.

In order to solve the major problem of SME financing more effectively, banks are facing the credit risk existing in the new business model through the online supply chain finance . The credit risk of online supply chain financing model, as the name implies, is the credit risk arising from issuing loans under the mode of online supply chain finance. It is a special case of credit risk. 


\section{B. The Characteristics of Credit Risk}

Several basic characteristics of credit risk are summarized as follows[1]:

- Endogenesis of credit risk. Endogenesis is the most characteristic of credit risk. Endogeneity is the debt default or not directly related with the lender itself. Therefore, the lender's creditworthiness and repayment willingness and ability to the bank must be accurately tracked from time to time and understand the detail[21]. Bank tracking SME credit status changes are mainly through: First, access to financial information of SMEs, such as financial reports; the second is to use the bank establish the credit rating system. However, both channels for information need banks to spend a certain amount of manpower material and financial resources and lack of timeliness reliability and effectiveness. Due to the small size of SMEs[19], not listed and other characteristics of their own limitations, we can not though the authoritative credit rating agencies to obtain effective credit information; we also can not use the secondary market price information to understand the financial status and default possibility of enterprises. If only a little of information obtained through the above two methods, we will not find potential SME clients[25]. The construct of online supply chain financing platform has made the bank access the credit information more easily. The provision of credit information of ecommerce by third-party B2B e-commerce enterprises can more fully capture the credit information of SMEs. Establish a credit risk assessment system that is more suitable for this new type of business.

- Asymmetry of risk and return. In the past, scholars assumed that the market risk showed a normal distribution. This is because it is almost impossible for the market price to stay away from the expected value, probably on the opposite side of the expected value. However, in reality, the market risk not obey the standard normal distribution, and it is likely to be the form of spikes and thick tails. Therefore, the basic characteristics of credit risk in the market can not be fully reflected in this assumption. The distribution of credit risk is biased. Because the they are inherently asymmetric: a small probability of a small gain for a bank, and a small probability of a greater loss for a loan business.

- Obvious non-systematic features. Not only systemic risks such as economic crisis but also macroeconomic cycle affect credit risk, under normal circumstances, some non-systematic micro-factors such as the financial status of the lender, operating ability, repayment ability and repayment willingness will affect the credit risk extently. However, when banks in the business practice, the credibility of old customers more easily obtain bank loans, and SMEs are indeed impossible to obtain financing through bank loans.

- Credit risk data is difficult to obtain. In the assessment of credit risk, the more difficult part is the objective evaluation of credit risk. The main reason is that banks' lones do not have a secondary market. Therefore, their poor liquidity in the secondary market makes it difficult to obtain data because fewer transactions can be made available to the lending business database.

\section{Credit Risk Evaluation Method}

1) Traditional credit risk evaluation model.

Before analyzing the modern credit risk management model, we need to briefly review the traditional credit risk management model. Because some of the ideas in the traditional credit risk assessment model also include in the modern credit risk assessment model partly, and almost all the credit risks are more or less linked, and even some new methods and models comes from the improvement of the traditional method. However, in the credit decision-making process the traditional credit risk assessment method the decisive factor is the intuitive qualitative analysis[28].

a) Credit risk evaluation method based on subjective analysis and traditional proportional analysis:

The characteristics of this stage assessment method are: Experienced credit experts hold the bank's credit decisionmaking power. A representative assessment method is the "5C" factor analysis method, which includes five factors: the borrower's character, capacity, capital, collateral and operating environment condition ,through this five qualities analysis the borrower's repayment willingness and repayment ability. Except the typical "5C" factor analysis, the more famous financial ratio comprehensive analysis are the DuPont analysis system and Wall Weight Grading. They are focus on the financial status of the company. But these can not meet the current banking business needs[2] . Although the credit risk evaluation method based on subjective analysis and traditional proportional analysis studies on some financial accounting indicators by calculating financial accounting data, it always uses a single variable to evaluate credit risk. This method has a serious flaw that is it does not rank and analyze the financial accounting indicators. It is not allow an accurate analysis of the strong and weak ratios of SMEs.

b) Credit risk evaluation method based on statistical analysis :

With the development of the social, new science and technology are gradually applied in the credit risk assessment and the multivariable method is also used to evaluate the credit risk. For example, Z-Score model and ZETA scoring model.The multivariate statistical analysis method is the basis of the Z-Score model by selecting multiple financial ratios of enterprises and assigning weights according to the size of the role and finally calculating the total discriminant score to predict the enterprise risk, we can judge the severity of the financial crisis [3]. The ZETA scoring model is based on the ZScore model with seven variables, more variables and a wider range of scalability, greatly improving the accuracy of credit ratings for companies. But also based on the analysis of corporate financial ratios.

c) Credit risk evaluation method based on mathematical model of credit rating:

Because a simple analysis of the financial ratio has been unable to meet the needs of practice. Therefore, scholars 
combined qualitative analysis and quantitative analysis, and introduced the mathematical model in credit evaluation that will be more scientific and can more systematically and comprehensively evaluate the credit risk of enterprises. The fuzzy comprehensive evaluation method that the basic principle are that there are many ambiguous phenomena in the economy and the fuzzy membership function can be constructed to transform the qualitative analysis into the quantitative analysis to make a comprehensive evaluation of the corporate credit. Gray analytic hierarchy process, which combines gray system theory and analytic hierarchy process, based on analytic hierarchy process, calculates the appraisal value according to gray system theory and gets the comprehensive credit score of the enterprise.

\section{2) Modern credit risk evaluation model:}

In recent years, financial institutions are experiencing various exponentially increasing risks, thus putting higher technical requirements for credit rating models.At present, the credit risk evaluation models that are widely used are: the Risk Metrics is the risk control model used by JPMorgan to calculate VaR, the KMV's Credit Monitor Model, the JPMorgan credit scale model Credit Metrics. These models are based on a large number of market and bank credit data for analysis.

\section{a) VaR model:}

In 1993, the G30 Group proposed a VaR[22] (Value at Risk) method for measuring market risk. Based on this, the Risk Metrics risk control model introduced by J. P. Morgan to calculate $\mathrm{VaR}$ is widely adopted by many financial institutions[23]. VaR (Value at Risk) refers to the maximum possible loss of the value of a financial asset or portfolio under a certain probability level (confidence level) in a specific period of time in the future [4].

\section{b) KMV model:}

In 1997, the KMV Company in the United States San Francisco established the KMV model used to estimate the probability of default of borrowing companies [5]. The KMV model is a model for default forecast established by using modern option pricing theory, and it is a remedy to the deficiency of traditional credit risk assessment methods [6].

\section{c) Credit metrics model:}

The Credit Metrics model is a risk management product introduced by J.P. Morgan in 1997 to quantify credit risk. The most important feature of this model is the risk-value measurement model used to evaluate the assets of an enterprise. It proposes to use the mark-to-market system of futures to evaluate the risk changes of enterprises.

\section{Analysis of Factors Influencing the Credit Risk}

Therefore, based on the characteristics of online supply chain finance and the actual conditions of SMEs, we will analyze the credit risk evaluation index system from four aspects: industrial factors, the strength of SMEs, credit records and supply Chain strength to analyze its credit risk factors.

\section{1) Industrial factors:}

SMEs may have two kinds of risks of non-systemic risk and systematic risk in their business operation. Systematic risk is caused by changes in the macroeconomic cycle or industry development. When recognize the credit risk based on thirdparty B2B supply chain finance, industrial risk is serious one aspect.,therefore, we can examine the industrial risk from the following aspects [8].

\section{a) Macro environment:}

For a business, the macro environment is important where we can get relevant information about the company's growth, such as macroeconomic policies. If the macroeconomic is not good, the risk of SME loans will rise, banks need to pay attention and take appropriate risk control measures.

\section{b) Pledge property:}

Throughout the industry, the price stability and passage of the pledged property can also clearly characterize the stability and development of the entire industry.

\section{2) SME strength:}

In the third-party B2B supply chain finance, SMEs can enhance their credit rating by using of the strength of core enterprises and supply chains. However, SMEs, as the recipients of loan funds, have their own indicators and overall power, which affect SMEs' repayment willingness and repayment ability. Therefore, in the bank credit rating, various risk factors of SMEs has becomed even more important. Among them, the factors affecting the credit rating of SMEs include: basic qualifications, operational capacity, profitability, innovation, development capability, solvency and credit quality and so on [9].

\section{3) Credit history:}

\section{a) Financial credit:}

The status of corporate credit is generally the focus of bank review, reflecting the repayment ability and willingness of enterprises. Due to the imperfect credit evaluation system in our country and the low default cost of small and medium-sized enterprises, it may cause the intentional default of the enterprises and bring losses to the banks. Therefore, when reviewing the credit, the credit records of the enterprises will be mainly investigated.

\section{b) E-commerce credit level:}

The biggest difference in Internet + Supply Chain Finance and supply chain finance is the use of Internet technology that is the electricity supplier companies to build third-party B2B supply chain financing platform based on e-commerce business and use the e-commerce credit system credit information to add the bank inadequate financial credit data to better identify potential high-quality SME clients. Indicators measured mainly include online application time, online transactions, online trading volume, online credit rating and SME customer evaluation.

\section{c) Financing platform credit record:}

There are also many data that can be tapped on the Internet supply chain financing platform. Combining with different business models, the indicators reflecting solvency mainly include the following: the financing amount of the member enterprises on the platform, the number of financing, the amount of credit Percentage and so on. 


\section{4) Supply chain strength:}

Based on the third party's B2B supply chain finance, the core idea is to examine the overall operation and trading status of the supply chain of the enterprise instead of separately examining the financial risk of SMEs, combined with several other factors comprehensively evaluate the credit rating of SMEs and determining the credit rank [10]. According to the content we will mainly study from the following aspects.

\section{a) Core business strength:}

The core enterprise strength plays an invisible guarantee role for small and medium-sized enterprises. The production level and management ability of SMEs can be reflected by this factor. The strength of core enterprises can be measured by the following indexes: status of core enterprises, assets and liabilities of core enterprises Rate, the core business profit margins.

\section{b) Supply chain competitiveness:}

Mainly through the overall strength of the supply chain to determine the level of competitiveness of SMEs, if the competitiveness of enterprises is strong, you can maintain a long-term cooperation with the core business, which is easier to obtain credit and you can evaluate from two aspects of the consumer products Satisfaction and product quality competitiveness.

\section{c) Supply chain cooperation:}

The cooperation between upstream and downstream firms in the supply chain will affect the bank's credit rating. If the relationship between firms is closer and there will be more cooperation, they will establish long-term and stable supply and demand relations. The closer this relationship, more the less sufficient for SMEs will be diluted.

Information sharing not only directly reflects the smooth communication between enterprises in the supply chain, but also reflects the extent of enterprise information sharing it have a direct impact on every aspect of the supply chain and business, and its measurement indicators mainly include sustainable transactions, close cooperation between upstream and downstream enterprises, upstream and downstream information sharing and so on.

\section{OPERATIONAL RISK}

\section{A. Definition of Operational Risk}

The expression of operational risk at home and abroad are also different. Different meanings and subjects determine different management modes. According to the definition of operational risk in the most authoritative Basel Capital Accord and the online supply chain finance, this paper considers that the operational risk refers to the risk that in the financial activities of Internet supply chain, due to procedural defects, personnel errors, technical failures, failure of financial institutions and failure caused by external factors and cause the loss to financial institutions.

\section{B. Classification of Operational RIsk}

As can be seen from the foregoing, the synergic operational framework of online supply chain finance realizes the unification of business flow, capital flow, information flow and logistics, which is referred to as "four-flow unification." Operational risk is also hidden in the four major trading stages, the four major transactions are often intertwined to interact with each other, may lead to operational risk events. In view of this situation, according to the specific aspects of risk can be classified as online financing risk, e-commerce risk, logistics risk and online payment risk, as follows:

- Online financing risk. Online financing risk is mainly generated in the online financing process, several major steps of online financing also lurk operational risk. In this regard, in credit, not only to adhere to the legal rigor of the contract and the strict credit process, but also pay attention to the scientific method [11]. In terms of financing approval, we must uphold the authenticity of the object of approval and the compliance and rigor of the procedure. In the subsequent management phase, we must uphold the management's non-slackness and pay attention to the possibility of parties' default. In addition, system stability and hardware security are also important aspects of online financing risk.

- E-commerce risk. In the e-commerce transaction phase, the main transaction happened in the core supply chain companies and other upstream and downstream enterprises, the authenticity of the transaction is the basis of the financial activities of the Internet supply chain. The operational risk at this stage is also mainly from the transaction, it should pay attention to the authenticity of the transaction management and effectively prevent false transactions.

- Logistics risk. In the logistics trading stage, with higher operational risk occurrence probability are mainly in the logistics warehouse supervision and logistics delivery and delivery, and the commercial banks need to strengthen the monitoring of the credit supporting assets. In the logistics phase of the risks are mainly noncompliance operations, credit losses cause the loss.

- Online payment risk. Online payment transaction stage, bank account payment and corporate payment back is the risk point of operation risk. The risk in this phase is mainly caused by personnel and system, for example, mistakes of accounts due to personnel errors, or due to system-induced payment errors .

\section{Operation Risk Identification Method and Selection}

- Questionnaire method. The method of questionnaire survey refers to the method that investigators do not enter the site but through the issuance of audit forms or other forms of questionnaires to identify the operational risk of online supply chain financial operations. The method mainly focuses on the questionnaire prepared by the risk management department of financial institutions and analyzes the current situation of financial operational risk management in supply chain by collecting the questionnaires and evaluating them. When preparing the questionnaire, the respondents may refer to the internal and external historical loss database and consider about the knowledge, literacy and attitudes that the respondents have. Survey method 
used correctly depends mainly on the scientific, rational, limited and applicability of the questionnaire, so the method of questionnaire quality requirements are relatively high.

- Flow chart method. Flow charts analysis is a flow chart drawn from the business operations and product operations processes in the online supply chain finance. Based on past history, experts and others then identify the risk points that may cause losses during the operation [13]. The flowchart can explain relevant information in the business operations and product operation flow to show the movement in the system. Flow chart can help decision-making, so that business managers more clearly find the problem will appear in a probable area, so as to formulate a program that can avoid operational risk. The flowchart method is a kind of identification method applied by many Internet supply chain finance at present.

- Expert investigation method. The method of specialist investigation is a method of identifying financial risks using the collective wisdom of experts. This method consists of working groups of experts in the fields of risk management department and business department to make judgment on the operational risk of online supply chain finance. The expert investigation method mainly includes expert conference method, brainstorming method and Delphi method.

- Scenario Analysis. Method of scenarios analysis is a scenario simulation of the environment in which the research subject is located. Each scenario describes a future state of the research subject and simulates and analyzes changes in the impact factor and predicts the likelihood of future scenarios, in order to examine the important factors that cause the associated risks and their impact size. In financial risk management, the most commonly used scenario analysis method that can measure the risk of extreme events is stress experiment. The method of scenario analysis is generally applicable to the analysis of financial products newly developed and can be used to identify the subject to be researched in advance.

- Fuzzy Set Analysis. The method of fuzzy set analysis is an analytical tool based on fuzzy mathematics that can solve the problem of fuzzy events. Fuzzy set analysis includes fuzzy pattern recognition, fuzzy clustering analysis and fuzzy comprehensive evaluation. Evaluation method for a fuzzy event analysis need to consider the impact of many factors, and according to the degree of different factors' impact on the evaluation, using different weights and measures to evaluate the study, the qualitative evaluation transform into the quantitative evaluation [14].

- $\quad$ Fault Tree Analysis. The Fault Tree Analysis (FTA) is a method of resolving possible faults into different levels of glitches in the form of logical diagrams [15]. The FTA method can not only qualitatively analyze failure risks, but also conduct quantitative analysis.
Fault tree analysis can describe the risk of complex systems and identify risk, and based on objective facts have great reliability. Graphical interpretation of fault tree analysis can be a specific operational risk failure layer by layer to study and reflect the different events and the logical relationship between system failures.

The above six risk identification methods can identify the operational risk of online supply chain finance, but there are still some shortcomings in the practical application. The research is not very clear many of the identification method is only classified in different categories of operational risk, not from the deep logic of the online supply chain financial operational risk. The advantages and disadvantages of various operational risk identification methods are shown in Table 1.

TABLE I. IDENTIFICATION METHODS ANALYSIS

\begin{tabular}{|c|c|c|}
\hline & advantages & disadvantages \\
\hline $\begin{array}{l}\text { Questio } \\
\text { nnaire } \\
\text { method }\end{array}$ & $\begin{array}{l}\text { Small input } \\
\text { costs, the survey } \\
\text { results to collect } \\
\text { and organize } \\
\text { conveniently }\end{array}$ & $\begin{array}{c}\text { The } \\
\text { requirements of } \\
\text { the questionnaire } \\
\text { designer is } \\
\text { relatively high }\end{array}$ \\
\hline $\begin{array}{l}\text { Flow } \\
\text { chart } \\
\text { method }\end{array}$ & $\begin{array}{l}\text { Conducive to } \\
\text { optimizing the } \\
\text { process }\end{array}$ & $\begin{array}{l}\text { Higher initial } \\
\text { investment costs }\end{array}$ \\
\hline $\begin{array}{c}\text { Expert } \\
\text { investigatio } \\
n \text { method }\end{array}$ & $\begin{array}{l}\text { The evaluation } \\
\text { result is more } \\
\text { accurate }\end{array}$ & $\begin{array}{l}\text { A longer time, } \\
\text { higher input costs }\end{array}$ \\
\hline $\begin{array}{l}\text { Scenario } \\
\text { Analysis }\end{array}$ & $\begin{array}{l}\text { Prior to the } \\
\text { risk before }\end{array}$ & $\begin{array}{l}\text { Accuracy is } \\
\text { low }\end{array}$ \\
\hline $\begin{array}{c}\text { Fuzzy } \\
\text { Set Analysis }\end{array}$ & $\begin{array}{c}\text { More } \\
\text { scientific, realistic } \\
\text { assessment of the } \\
\text { quantitative }\end{array}$ & $\begin{array}{l}\text { Computational } \\
\text { complexity, the } \\
\text { index weight more } \\
\text { subjective }\end{array}$ \\
\hline $\begin{array}{l}\text { Fault Tree } \\
\text { Analysis }\end{array}$ & $\begin{array}{l}\text { Logically } \\
\text { strong }\end{array}$ & $\begin{array}{l}\text { Spend more } \\
\text { time }\end{array}$ \\
\hline
\end{tabular}

By comparing different operational risk identification methods in Table 1 , it is found that the fault tree analysis method with its unique image deduction, can make further research on the operational risk of the target one by one. The fault tree analysis not only reflects the relationship of online supply chain financial system operational risk within the different risk factors, but also reflects the logic relationship of basic events intermediate events and top events in the operational risk. It is more suitable for identifying Internet supply chain financial operational risk.

\section{MARKET RISK}

Market risk refers to the risk of uncertain value or return of financial products due to the fluctuation of interest rate, exchange rate, stock market, price and other factors. Market risk mainly includes interest rate risk, exchange rate risk, stock market risk and price risk. 
The marketization of interest in our country is not yet mature or not fully mature. The pricing of bank supply chain financing products still adopts the fixed interest rate as the traditional working capital loans. Once the interest rate changes, the bank can't adjust the interest rate in time and can't make any adjustment until the beginning of the next benchmark year. This also exposes banks to the risks of interest rates. In addition, there is a lot of business in supply chain finance that is international trade. In international trade, whether single import or export business or back-to-back letter of credit transactions, if not using the same currency will have exchange rate risk. In the free-market economy, the volatility of commodity prices is a normal phenomenon. It is also more likely that the prices will fluctuate within a certain period of time. Therefore, there is also a price risk in the supply chain finance business.

\section{REFERENCES}

[1] Li Yixue,Supply chain financial risk assessment [J],Central University of Finance and Economics, 2011 , pp.36-41.

[2] Xia Liming, et al.Study on the construction of SME credit risk assessment model [J] ,Journal of Economics and Management, 2011 , pp.103-105.

[3] Zhu Xiaodong, Zhang Zongyi, Geng Huadan.Analysis and Comprehensive Comparative Analysis of Modern Credit Risk Measurement Models [D],Finance and Economics Research, 2010, pp.34-46.

[4] Jin Zhibo, Wang Hongjuan.Comparison of Modern Credit Risk Measurement Models [J],Contemporary Economy, 2009 , pp.142-143.

[5] Matthew Kurbat, Methodolog for Testing the Level of the EDF credit Measure [J], Moodys KMV Corporation 2002, pp.26-28.

[6] Darrell Duffle, David Land,Term Structures of Credit Spreads with Incomplete Accounting Information,Econometrics, Econometrics, 2001, pp.633-664.

[7] Yuan Lili,China's small and medium commercial banks credit risk management research [D],Chengdu: Southwest University of Finance and Economics, 2013.

[8] Liu Xiuying,Research on credit risk evaluation of GEM listed companies based on gray system theory [D] ,Anhui: University of Science and Technology of China, 2010.

[9] Bian Ning ,SME supply chain financing model machine credit risk assessment [D],Wuhan: Wuhan University of Technology, 2008.

[10] Fan Xinmin,Study on the Risk of Default in Financial Supply Chain [D] ,Shanghai: Donghua University, 2011.

[11] Zhou Hui,Online Supply Chain Finance [D],Hunan University, 2014

[12] Zhang Jinqing,Financial Risk Management (Second Edition) [M],Shanghai: Fudan University Press, 2012, pp.63-69.

[13] Pan Biao,A clever use of component animation complex interactive interactive tree branch flow chart [J],Hefei: Computer Knowledge and Technology, 2013, pp.61-63.

[14] Yang Junqi, Hou Xiaokang, Yang Yijie.Studies on the performance evaluation system of party building based on fuzzy comprehensive evaluation model [J] ,Anzhou University, 2012, pp.64-72.

[15] Wei Xuanping,Fault tree analysis and its application [J],Computer Science and Technology, 2004 , pp. 43-47.

[16] LeonBusch.,Supply Chain Finance: The Next Big Opportunity[J],Supply Chain Management Review. 2014, pp.57 60

[17] Gupta, S, Dutta, K. Modeling of Financial Supply Chain[J],European Journal of Operational Research,2011, pp.47 56.

[18] Chopra S,Sodhi M. Managing risk to avoid supply chain break down.[J],MIT Sloan Management Review,2004, pp.53 61.

[19] DunhamA, UDELLGF. A More Complete Conceptual Framework for SME Finance[J],Journal of Banking\& Financing, 2004, pp.2945 2966.

[20] Michael Lamoureux. A supply chain finance prime[J],Supply Chain Finance, 2007, pp.34 48.
[21] Basu P, Nair S K. Supply chain finance enabled early pay: unlocking trapped value in B2B logistics[J],International Journal of Logistics Systems and Management,2015, pp.334 353.

[22] Bouchand,A VAR analysis informed by a DSGE model[J],Journal of Hydraulic Engineering, 2015, pp.12 22.

[23] Sentana,VaR as the CVaR sensitivity: Applications in risk optimization[J],Journal of Computational and Applied Mathematics, 2010, pp.43 51.

[24] HawneeK.Vickery, Roland.Managing the Finance Supply Chain [J],Supply Chain Management Review, 2003, pp.190 196.

[25] Cressy, R. Olofsson Christer. "The financial conditions for Swedish SMEs: Survey and Research Agenda “. Small Business Economics, 1997, pp.179-194.

[26] Badr Y., Stephan J.. Security and Risk Management in Supply Chains [J],Journal of Information Assurance Security, 2007, pp.287-296.

[27] Barsky $\cdot \mathrm{N} \cdot \mathrm{P}$, Catanach $\cdot \mathrm{A} \cdot \mathrm{H}$. Evaluating business risks in the commercial lending decision[J],Commercial Lending Review,2005, pp.3-10.

[28] Demoulin, Embrechts,Value and risk assessment of supply chain management improvement projects[J],Int.J.Production Economics 2006, pp.186-201. 